\title{
Clinical Engineering Role in the Development of Emergency Use Medical Devices
}

\author{
By Roberto Ayala
}

CE/HTM Consultant, Mexico

\begin{abstract}
Clinical Engineering (CE) professionals have a crucial role in healthcare institutions during the pandemic caused by the COVID-19 disease, mainly by supporting the front line by allowing the proper and timely access to the medical equipment required to diagnose and treat patients affected. But another one of their roles, probably not so expected, has been their contributions to the development of emergency use medical devices, especially those for respiratory and oxygen therapy. Using the case of critical care use ventilators, and as presented during an IFMBE-CED webinar on the topic, this paper mentions the role of CE for the rapid response manufacturing of such vital care devices in three main aspects: development, regulation, and education. The results from such efforts have paid off by having safe and efficient support equipment while the shortage from commercial products has been receding, by establishing international guidelines for future innovators to take into consideration, and by leaving valuable knowledge in the form of educational and training videos for future generations to consult from.
\end{abstract}

Keywords - Clinical engineering, medical devices, ventilators, pandemic.

Copyright (C) 2021. This is an open-access article distributed under the terms of the Creative Commons Attribution License (CC BY): Creative Commons - Attribution 4.0 International - CC BY 4.0. The use, distribution or reproduction in other forums is permitted, provided the original author(s) and the copyright owner(s) are credited and that the original publication in this journal is cited, in accordance with accepted academic practice. No use, distribution or reproduction is permitted which does not comply with these terms.

\section{INTRODUCTION}

COVID-19 pandemic put healthcare and industry systems to the test, and it has been evident that healthcare professionals and workers were in the middle of it all. CEs were no exception, and their responsibilities doubled as they were required to look after the medical technology needs of front-line workers and the rest of the clinical services personnel. CEs did not hesitate when new challenges required their skilled efforts. For example, early in the pandemic expansion, there was a shortage of several types of medical devices needed for respiratory and oxygen therapy, and one, in particular, was the most indemand - ventilators for critical care units. As it became clear that the industry was struggling to cope with the shortage, several technical groups, including academia, professional organizations, and non-medical devices companies, started their own efforts to build locally produced ventilators. However, they soon realized that it was necessary to consult CE professionals with expertise in this vital equipment's use, technical specifications, safety considerations, and normative and regulatory concerns. 
This collaboration focused on three main areas: contributions to the design and development of ventilators, health regulation considerations, and education and training.

\section{Clinical Engineering Role in the Development of Medical Devices}

Medical device design and development is no easy task, especially with equipment that operates using mechanical, electrical, electronic, and pneumatic components, such as vital support devices like ventilators. Many of the initial initiatives were non-invasive ventilation mechanisms that certainly couldn't comply with safety and performance standards, and that's where CEs entered the scene to help with the efforts. CEs contributed to the manufacturing of locally produced, emergency use ventilators with actions such including:

- Putting engineering knowledge and skills together with the development of the devices.

- Helping companies, academia, researchers, and investors to identify clinical needs and the right normative and tech specs for this type of device.

- Testing the prototypes and finished products through the proper metrology practices.

\section{Clinical Engineering Role in Health Regulation}

No matter how urgent the need for a medical device may be, the authorization process must be approved by a competent health regulatory authority because such a device needs to prove its safety and efficacy. In the pandemic, authorities understood that they had to offer fast-tracking processes without losing their objectives related to the emergency use authorizations. Once again, CEs stepped up as the connection between the regulatory process and unexperienced ventilators developers with some of the following interventions:

- Identifying international standards and normative and best practices to establish a local, applicable normative.

- Developing technical specifications for local production based on established specifications but adjusting as necessary for a proper response.

- Support WHO/PAHO efforts for worldwide use guidelines and other relevant technical documentation.

\section{Clinical Engineering Role in Education}

Because of their multidisciplinary approach, clinical engineers are well known as skilled trainers and educators, and this aptitude has helped share knowledge and experiences regarding the manufacturing, principles, operation, care, and safety topics for critical care use ventilators. In a world that was forced to social distancing, the use of web-based meeting platforms was rightly exploited for these purposes of education and training, something that clinical engineers used in the form of: (1) webinars on diverse topics related to patient ventilators, (2) training courses on manufacturing and standards applications, and (3) calls with other health professionals around the globe to exchange knowledge and experiences.

One prime example of the noble and vital role of knowledge sharing has been the efforts from IFMBE-CED, which right away began with organizing and offering relevant webinars, with helping hands from experts from all corners of the World and with a variety of topics regarding clinical engineering approach for the pandemic.

\section{CONCLUSIONS}

CE has been evolving almost at the same pace as medical devices increase in complexity, from participating in service and safety checks, going through integral management, and even collaborating with policymaking at a national health system level. These evolving skills now can cover research, innovation, and development of medical devices, and the pressing circumstances of the COVID pandemic just set the stage for clinical engineers worldwide to showcase such abilities. The challenge now is to write down the experiences in scientific papers and pass the knowledge to younger generations because the inertia to strengthen these skills shouldn't be subjected only to health emergencies. There is a lot of health technology yet to be discovered.

\section{REFERENCES}

1. Forbes Staff. Gobierno de AMLO presenta ventiladores hechos en México para atender COVID-19. Forbes. México CDMX. Forbes Staff; 2020. Available at https://www. forbes.com.mx/politica-gobierno-de-amlo-presentaventiladores-hechos-en-mexico-para-atender-covid-19/. 
2. World Health Organization. Priority medical devices list for the COVID-19 response and associated technical specifications. WHO. 2020. Available at https://apps. who.int/iris/handle/10665/336745

3. IFMBE-CED. IFMBE-CED courses/webinars. Author; 2020. Available at https://ced.ifmbe.org/resources/ courses/gurupcategs.html
4. Gobierno de Mexico. Información sobre los lineamientos de ventiladores. COFEPRIS. México CDMX; 2020. Available at https://www.gob.mx/cofepris/articulos/ informacion-sobre-los-lineamientos-de-ventiladoresactualizacion-9-de-mayo?idiom $=\mathrm{es}$

5. Biomédicos de México. Canal de videos del Colegio de Ingenieros Author. CIB YouTube. México; 2020. Available at https://www.youtube.com/channel/ UCyUCzX_6BeEMz26HxAZy3vg 